
\title{
28 Research Square \\ Virtual Implant Rehabilitation Of The Severely Atrophic Maxilla: A Radiological Study
}

\section{Michele Manacorda}

Universita Vita Salute San Raffaele

Bianca Poletti de Chaurand ( $\boldsymbol{Q}$ b.polettidechaura@studenti.unisr.it )

Universita Vita Salute San Raffaele https://orcid.org/0000-0001-7320-1709

\author{
Alberto Merlone \\ Universita Vita Salute San Raffaele \\ Giulia Tetè \\ Universita Vita Salute San Raffaele

\section{Paolo Capparè} \\ Universita Vita Salute San Raffaele \\ Raffaele Vinci \\ Universita Vita Salute San Raffaele
}

\section{Research article}

Keywords: Oral surgery, Implant planning, Maxillary atrophy, Implant rehabilitation, CBCT, Tilted implants.

Posted Date: November 11th, 2019

DOI: https://doi.org/10.21203/rs.2.13063/v2

License: (c) (i) This work is licensed under a Creative Commons Attribution 4.0 International License.

Read Full License 


\section{Abstract}

Background: Advanced maxillary atrophy is often observed and implant placement could become difficult. Nevertheless, a volumetric evaluation using a proper diagnostic software could facilitate the implant planning. The purpose of the present study is to suggest the potential application of the maxillary retro-canine area as the designated place for virtual tilted implants also in severely atrophic maxillae.

Methods: A sample of CBCT images from the Department of Dentistry (IRCCS San Raffaele, Milan) was evaluated. After a 3D anatomical evaluation of the maxilla tilted implants has been virtually positioned in the retro-canine regions. All the implants were inserted with the same procedure at $30^{\circ}$ and $45^{\circ}$ degrees of tilting. The length, the palatal angulation and the diameter of each implant were identified.

Results: 220 tilted implants were placed. An average implant measurement of $13.508 \mathrm{~mm}$ of length and $3.42 \mathrm{~mm}$ of diameter were calculated. Also, an average buccal-palatal angulation of $6^{\circ}$ was identified. After the statistical analysis implant length was found significantly higher at $45^{\circ}$ degrees than at $30^{\circ}$ degree $(<0.0001)$.

Conclusions: A considerable amount of patients show a significant degree of bone atrophy. The implantsupported treatment plan can rely on the three dimensional imaging of the residual bone as a guiding tool to establish the most effective implant position for each specific case. In this study it is founded that an implant could be longer if its mesio-distal angulation is more accentuated. In addition, it is possible to virtually insert tilted implants also in severely atrophic maxilla. This could help clinicians to consider the retro-canine area a viable place to insert longer tilted implant.

\section{Background}

The growing ageing population and the psychosocial perception of tooth loss have both contributed to increase the implant-supported solutions ${ }^{1-3}$. Throughout the past twenty years the use of osseointegration methods has grown more and more critical for oral rehabilitation, to completely regain functions and improve aesthetics ${ }^{4}$. This is also due to the frequency of disapproving patient outcomes with the use of removable partial or total dentures ${ }^{5-6}$. One of the most important requirements for dental implants osseointegration is the presence of a sufficient amount of basal bone ${ }^{7}$. Unfortunately, totally or partially edentulous maxillae often show a significant degree of sinus pneumatization and/or alveolar bone atrophy ${ }^{8}$. This lack of bone may complicate the implants placement and could influence the final results ${ }^{9}$. For these reasons, several aspects should be considered before the implant surgery and a 3D volume bone evaluation is essential to plan a proper implant rehabilitation ${ }^{10}$.

The Cone Beam Computed Tomography (CBCT) produces three-dimensional reconstructions of maxillary and mandibular anatomical structures using a single scan and offering multiple views with low radiations. A flat detector makes the capture. The X-ray diffusion is cone shaped. The CBCT scans 
permits to gain a better understanding of the jaws' morphology and to evaluate the volume of remaining bone in any given site. Furthermore, the scans allow interactive planning using 3D simulation software. To date, according to the American Academy of Oral and Maxillofacial Radiology, CBCT should be considered as the method of choice for the three dimensional evaluation of the maxillary bone to plan an implant treatment ${ }^{11}$. In particular, volumetric data acquired by CBCT showed a high accuracy of the measurements with a relative error below $1 \%$ compared with the same measurements took in vivo as demonstrated by Veyre-Goulet et al ${ }^{12}$. Many surgical techniques are suitable to place and load implants in edentulous atrophic maxilla. Treatment plans may include bone grafting techniques to reconstruct the lost bone volume ${ }^{13}$. For example procedures such as distracting osteogenesis, Le Fort osteotomy with inlay grafting, onlay bone grafts, maxillary sinus floor elevation or guided bone regeneration have been used to re-establish bone bulk before implant surgery ${ }^{14-17}$. However, these methods are all characterized by high morbidity and long duration of the therapy ${ }^{18-19}$. In addition, patient satisfaction with graftless solutions for implant rehabilitation of edentulous jaws is generally high ${ }^{20}$. Widmark et al. ${ }^{21}$ found that implants inserted in native bone had a higher success rate than implants placed into grafted bone. The trans-sinus and zygomatic implants are viable alternatives for treatment of the severely atrophic maxilla, nevertheless this procedures are operator-dependent ${ }^{22}$.

In this study, tilted implants insertion is simulated on CBCT scans of atrophic upper jaws in order to calculate the average angulations and measures of the fixtures.

The aim of the present paper is to suggest the potential application of the maxillary retro-canine region as the designated place for virtual "iuxtameatal" implants. "luxtameatal" means that the apex of the implants is surrounded by the cortical bone near the nasal inferior meatus. This virtual procedure could help surgeons finding the most effective implant measures and position in order to get more implant stability and considering a tilted implant rehabilitation without the need of sinus lifts or invasive bone grafting operations in patients presenting a severe maxillary atrophy.

\section{Methods}

\section{Study Population}

Patients were retrospectively selected among those referred for a Cone Beam Computerized Tomography (CBCT) to the Department of Dentistry, IRCCS San Raffaele Hospital, Milan, Italy from December 2015 to January 2018.

Patients were included according to the following criteria:

- Age $>18$ years old

- Edentulous mid-maxilla area (at least from the second molar to the canine)

- Atrophic maxilla with a residual flat or depressed ridge form with less than $5 \mathrm{~mm}$ in height (i.e. from the lowermost point of the maxillary sinus floor and the most coronal point of the residual crest) 
Patients were not included if they presented one of the following exclusion criteria:

- Radiolucent or radiopaque images in the mid-maxilla area

- Implant or impacted tooth in the mid-maxilla area

The "mid-maxilla" region is an anatomical district that belongs to the maxillary bone. It is extended from the lateral nasal cavity's wall until the medial wall of the maxillary sinus cavity, including also the residual alveolar process below the sinus floor (Fig. 1). The mid-maxilla could be also identified with the retrocanine bone triangle $\mathrm{e}^{23-24}$.

Each patient provided a written consent before undergoing the CBCT scan. No one refused to sign the informed consent.

All CBCT scans were acquired with a Field of View of $12 \times 8 \mathrm{~cm}$, at $90 \mathrm{kV} 10 \mathrm{~mA} 16 \mathrm{~s}$ and 0,2 mm Voxel size with a NewTom VGi evo Cone Beam 3D Imaging Device (Cefla SC, Imola Italy). The default position and orientation of the orthogonal sectional planes relative to the jaws were consistent in all the CBCT datasets of each patient. To guarantee a stable head position, all CBCT scans were checked and reorientated to place the scan view parallel to the Camper's plane.

\section{Virtual luxtameatal Implant Positioning}

The residual bone of each scan was analyzed using the panorex imagine construction (Fig. 2). According to the software procedures the panorex image was obtained drawing a panoramic curve on the axial view of the maxillary segment above the residual alveolar crest. The cross sectional views perpendicular to the panoramic curve were automatically elaborated by the software.

For each patient, two iuxtameatal cone shape implants were virtually placed in tilted position in each side, at $30^{\circ}$ and at $45^{\circ}$ degrees of mesio-distally angulation (Fig. 3). The majority of implant companies produces abutments which can correct an angle of $30^{\circ}$ maximum, but the prosthesis meso-structure can correct additional $15^{\circ}$ of angulation with its conic component, so that the maximum of angulation could be $45^{\circ}$. All tilted implants were placed in analogous way, according to the All-on-four procedure described by Malò et al. ${ }^{25}$ trying to maximally exploit all the bone volume offered with at least $2 \mathrm{~mm}$ of bone all around the fixtures (Fig. 4).

Implant insertions were simulated with the RealGUIDE 5.0 implant planning software (3DIEMME, Cantù, Italy).

\section{Outcome measures}

Once the iuxtameatal implants were positioned in the mid-maxilla, the length and the diameter of the implants were measured. The buccal-palatal angulation of each implant were analyzed too in the cross 
sectional views. A negative angle indicated that the implant insertion went from the palatal side to the vestibular side of the residual alveolar crest. With the dedicated software also the bone density around the implants' apex was measured in gray-scale. All measurements were performed using a digital ruler at $0.1 \mathrm{~mm}$ increments by a single trained examiner (A.M).

\section{Statistics}

All statistical analyses were performed with a specific software $(R, R$ Core Team, Foundation for Statistical Computing, Vienna, Austria). To evaluate the effect of the tilting degree ( $30^{\circ} \mathrm{vs} .45^{\circ}$ degrees) on the implant length, a linear mixed-effects model was estimated. In particular, the Linear and Nonlinear Mixed Effects models package was used to estimate the Linear Mixed Effects model (Pinheiro J., Bates D., DebRoy S., \& Sarkar D. R Core Team package version 3.1-137 2018).

The modelling approach here applied allows to properly account for repeated measure data and for unobserved heterogeneity among patients. Actually, along with fixed effects, the model allows to specify in the model random components. An initial complete model was estimated including position and tilting degree as fixed effects along with their interaction. Subject-specific random effect was specified. Hence, a random intercept model was considered. Assumptions for the correct application of the model were checked. A backward stepwise procedure was applied to select a more parsimonious model.

In all the analyses, the significance threshold was set at 0.05 .

\section{Results}

CBCT scans of 59 subjects ( 28 male and 31 females; mean age: $64.5 \pm 8.2$ years)

were included in this study according to the inclusion criteria. Only two scans showed a very severe maxillary atrophy in both right and left maxillae. Among the other 57 scans, one of them presented the right maxilla completely reabsorbed and other three presented the left maxilla too narrow to place any implant.

A total of 220 iuxtameatal implant insertions were simulated (see additional file 1). An average implant measurement of $13.508 \mathrm{~mm}$ of length and $3.42 \mathrm{~mm}$ of diameter were calculated (Tab. 1). Also, an average anterior-posterior angulation of $6^{\circ}$ were identified. In some simulations the implant axis was negative: the fixtures' most coronal point was palatal respect of the apex. The average bone density around implants was 570 gray-scale. After the statistical analysis implant length was found significantly higher at $45^{\circ}$ degrees than at $30^{\circ}$ degree $(<0.0001)$. Thus, when considering tilting degree of the implant, significant effects of implant length were found (Fig. 5).

\section{Discussion}


Krekmanov et al. ${ }^{26}$ and Aparicio et al. ${ }^{27}$ presented the first papers in which a combination of tilted and axial implants was used in patients with severely reabsorbed posterior maxillae. The results indicate that the use of tilted implants is an effective and safe alternative to maxillary sinus floor augmentation or bone grafts procedures.

Peñarrocha-Oltra et al. ${ }^{28}$ in 2013 wrote that tilted implants, both used alone and combined with axially placed implants and rehabilitated with different prosthetic options have high success rates, minimal complications and high patient satisfaction.

Additionally, Balleri et al. ${ }^{29}$ presented a very good outcome with 20 fixed partial dentures supported by two implants, one tilted and one axial, in the retro-canine bone triangle. In a recent finite element study for two splinted implants, it appeared that tilting of the distal fixture does not stress the peri-implant bone as compared with the mesial axial fixture ${ }^{30}$. It was also demonstrated that tilted posterior implants were mechanically more advantageous than distal cantilever units ${ }^{31}$. Finally, the study of Barnea ${ }^{32}$ demonstrates no effect of implant angulation on peri-implant bone loss in the posterior maxilla. Nunes et al. ${ }^{33}$ Analyzed the width and the height of bone volume of the edentulous posterior maxilla using CBCT scans from 122 patients. They found that a high percentage (54\%) of molar edentulous sites exhibited a reduced bone height (less than $5 \mathrm{~mm}$ ) and do require a sinus floor elevation procedure if implant therapy is chosen as a treatment option. However Nunes et al. did not take in consideration the possibility of tilted implants placement. On the contrary, Tolstunov et al. ${ }^{34}$ measured the average bone volume of the edentulous maxilla with cone-beam computerized tomography scans from 30 patients and determined its suitability for implant treatment without additional bone grafting. The results indicated that in many maxillary edentulous cases the existing bone volume can be often enough for a full-arch maxillary implant treatment with also tilted implants, without an additional trauma or expense associated with bone grafting or sinus lift.

Candel Marti et al. ${ }^{35}$ Evaluated soft tissue conditions and bone loss around palatal positioned implants supporting fixed full-arch prostheses to rehabilitate edentulous atrophied maxillae and compare them with conventional well-centered implants placed in non-atrophic maxillae after a minimum follow-up of 5 years. The results suggested that palatal positioned implants may be a good treatment alternative for patients with severe horizontal maxillary alveolar bone atrophy.

Owing to mechanical and anatomic difficulties, implant treatment in the atrophic maxilla represents a challenge.

The short and ultra-short implants in the posterior areas could be an alternative, but the trabecular compartment of the canine/premolar region offered higher quality when compared with the posterior maxilla. In addition, the basal bone showed a higher density than the alveolar bone. Corroborating the statement, Gonda et al. ${ }^{36}$ showed that premolar areas offer the most favourable scope in terms of bone height, width, angulation and quality. 
In this paper the examiners were able to find enough bone to adequately distribute the virtual tilted implants in all cases except two. This study presents some limitation such as the retrospective nature of the present analysis and the virtual placement of the implants. Nevertheless, the statistical analysis demonstrates that an implant could be longer if its angulation is more accentuated. Hence, tilting implants would allow inserting the fixture apex in a high bone density area. Longer iuxtameatal implants in the mid-maxilla area consent more implant stability and, eventually, an immediate prosthetic load ${ }^{37-38}$.

Benefitting from the virtual plan previously developed, the implants will unlikely exceed the cortical lamina of the nasal lateral wall. In the eventuality that it happens, the associated risks may be epistaxis, implant displacement in the nasal cavity and rhinitis. Nonetheless, this statement has to be confirmed through future clinical studies.

These tilted implants do not compromise implant placement in the anterior maxilla because they have a marked angulation in the palatal sense. But in the ortho-panoramic radiography the correct vestibularpalatal angulation of the implants cannot be planned: only CBCT scans can suggest the ideal angulation with extremely high precision. With this paper, clinicians could become aware of the importance of the 3D anatomical view to evaluate the amount of cortical bone around the nasal cavity and could learn the importance of simulation software to virtually insert implants also in severely atrophic maxillae.

Among CBCT scans gray-scales vary widely due to different factors, such as the lack of grey level uniformity, the presence of artifacts, the effects of scatter and beam hardening ${ }^{39}$. On the other hand, different studies demonstrated how grey levels of CBCT can be used to derive Hounsfield units ${ }^{40-41}$. The gray-scale outcomes reported in this study could suggest that the peri-implant bone density was greater than the average density of the cancellous bone. It indicates that the apex of the iuxtameatal fixtures is effectively inserted in the cortical bone of the walls of the nasal meatus.

No studies were found measuring the atrophic maxilla bone volume related to tilted implant treatment. The absence of similar studies in the scientific literature limits the founding of comparisons with other study.

\section{Conclusions}

A good anatomical background and an accurate tridimensional virtual plan before the implant surgery could help clinicians finding the best implant angulation and position. Surgeons should take advantage especially from the mid-maxilla area, the maxillary region with the highest bone density, in order to increase the implant stability. Within the limits of the present study, it can be concluded that inserting tilted implant in the mid-maxilla area could be virtually applied also to patients with severely atrophic maxillae, except for some rare cases. Further studies are needed to investigate the clinical use of these iuxtameatal tilted implants.

\section{Abbreviations}


CBCT: Cone Beam Computed Tomography

\section{Declarations}

\section{Ethics approval and consent to participate}

Written informed consent for publication of their clinical details and radiological images was obtained from all patients and the San Raffaele Scientific Institute ethical committee approved the study (number \#11/INT/2014)

\section{Consent for publication}

Not applicable

\section{Availability of data and materials}

The dataset supporting the conclusions of this article is included within the article (and its additional file). All materials described in this manuscript, including all relevant raw data, will be freely available to any scientist wishing to use them for non-commercial purposes, without breaching participant confidentiality.

\section{Competing interests}

The authors declare that they have no actual or potential financial relationships with any companies whose products or services may be related to the subject matter of the article.

\section{Funding}

The authors state that this work has not received any external funding.

\section{Authors' contributions}

MM conceived the idea;

BPdC approved the study protocol;

AM collected the data;

BPdC performed statistical analysis and drafted the manuscript;

PC and GT interpreted the data; 
$\mathrm{RV}$ and PC revised the manuscript;

$\mathrm{RV}$ carried out the final revision of the text and approved the idea.

All authors read and approved the final manuscript.

\section{Acknowledgements}

Not applicable

\section{References}

1. Okoro CA, Strine TW, Eke PI, Dhingra SS, Balluz LS. The association between depression and anxiety and use of oral health services and tooth loss. Community Dent Oral Epidemiol. 2012;40(2):134-44.

2. Roohafza $\mathrm{H}$, Afghari P, Keshteli AH et al. The relationship between tooth loss and psychological factors. Community Dent Health. 2015;32(1):16-9.

3. Pearce D, Bovagnet FC. The demographic situation in the European Union. Popul Trends. 2005; (119):7-15.

4. Taylor TD, Agar JR. Twenty years of progress in implant prosthodontics. J Prosthet Dent. 2002;88(1):89-95.

5. Shaghaghian S, Taghva M, Abduo J, Bagheri R. Oral health-related quality of life of removable partial denture wearers and related factors. J Oral Rehabil. 2015;42(1):40-8.

6. Xie Q, Närhi TO, Nevalainen JM, Wolf J, Ainamo A. Oral status and prosthetic factors related to residual ridge resorption in elderly subjects. Acta Odontol Scand. 1997 Oct;55(5):306-13.

7. Esposito M, Hirsch JM, Lekholm U, Thomsen P. Biological factors contributing to failures of osseointegrated oral implants. (I). Success criteria and epidemiology. Eur J Oral Sci. 1998;106(1):527-51.

8. Araújo MG, Lindhe J. Dimensional ridge alterations following tooth extraction. An experimental study in the dog. J Clin Periodontol. 2005;32(2):212-8.

9. Eufinger $\mathrm{H}$, König S, Eufınger A, Machtens E. Significance of the height and width of the alveolar ridge in implantology in the edentulous maxilla. Analysis of 95 cadaver jaws and 24 consecutive patients. Mund Kiefer Gesichtschir. 1999;3 Suppl 1:S14-8.

10. Benavides E, Rios HF, Ganz SD et al. Use of cone beam computed tomography in implant dentistry: the International Congress of Oral Implantologists consensus report. Implant Dent. 2012;21(2):78-86. doi:10.1097/ID.0b013e3182488

11. Tyndall DA, Price JB, Tetradis S, Ganz SD, Hildebolt C, Scarfe WC. Position statement of the American Academy of Oral and Maxillofacial Radiology on selection criteria for the use of radiology in dental implantology with emphasis on cone beam computed tomography.

Oral Surg Oral Med Oral Pathol Oral Radiol. 2012;113(6):817-26. 
12. Veyre-Goulet S, Fortin T, Thierry A. Accuracy of linear measurement provided by cone beam computed tomography to assess bone quantity in the posterior maxilla: a human cadaver study. Clin Implant Dent Relat Res. 2008;10(4):226-30.

13. Corbella S, Taschieri S, Del Fabbro M. Long-term outcomes for the treatment of atrophic posterior maxilla: a systematic review of literature. Clin Implant Dent Relat Res. 2015 Feb;17(1):120-32.

14. Waechter J, Leite FR, Nascimento GG, Carmo Filho LC, Faot F. The split crest technique and dental implants: a systematic review and meta-analysis. Int J Oral Maxillofac Surg. 2017 Jan;46(1):116128.

15. Le BT, Borzabadi-Farahani A. Simultaneous implant placement and bone grafting with particulate mineralized allograft in sites with buccal wall defects, a three-year follow-up and review of literature. J Craniomaxillofac Surg. 2014 Jul;42(5):552-9.

16. Raghoebar GM, Timmenga NM, Reintsema $H$, Stegenga B, Vissink A. Maxillary bone grafting for insertion of endosseous implants: results after 12- 124 months. Clin Oral Impl Res 2001;12:279-86.

17. Al-Dajani M., Recent Trends in Sinus Lift Surgery and Their Clinical Implications. Clin Implant Dent Relat Res. 2016 Feb;18(1):204-12.

18. Penarrocha-Diago M, Uribe-Origone R, Guarinos-Carbo J: Implant-supported rehabilitation of the severely atrophic maxilla: a clinical report. J Prosthodontics 13:187, 2004.

19. Seiler JG, Johnson J: Iliac crest autogenous bone grafting: donor site complications. J South Orthop Assoc. 2000 Summer;9(2):91-7.

20. Pommer B, Mailath-Pokorny G, Haas R, Busenlechner D, Fürhauser R, Watzek G. Patients' preferences towards minimally invasive treatment alternatives for implant rehabilitation of edentulous jaws. Eur J Oral Implantol. 2014 Summer;7 Suppl 2:S91-109.

21. Widmark G, Andersson B, Carlsson GE, et al: Rehabilitation of patients with severely resorbed maxillae by means of implants with or without bone grafts: A 3 to 5 year follow-up clinical report. Int J Oral Maxillofac Implants. 2001 Jan-Feb; 16(1):73-9.

22. Tuminelli FJ, Walter LR, Neugarten J, Bedrossian E. Immediate loading of zygomatic implants: A systematic review of implant survival, prosthesis survival and potential complications. Eur $\mathrm{J}$ Oral Implantol. 2017;10 Suppl 1:79-87.

23. Ganz SD. The reality of anatomy and the triangle of bone. Inside Dentistry 2006;2:72-77.

24. Ganz SD. Using interactive technology: in the zone with the Triangle of Bone. Dent Implantol Update. 2008 May; 19(5):33-8.

25. Maló P, Rangert B, Nobre M. All-on-4 immediate-function concept with Brånemark System implants for completely edentulous maxillae: a 1-year retrospective clinical study. Clin Implant Dent Relat Res. 2005;7 Suppl 1:S88-94.

26. Krekmanov L, Kahn M, Rangert B, Lindström H. Tilting of posterior mandibular and maxillary implants for improved prosthesis support. Int J Oral Maxillofac Implants. 2000 May-Jun;15(3):40514. 
27. Aparicio $C$, Perales $P$, Rangert $B$. Tilted implants as an alternative to maxillary sinus grafting: a clinical, radiologic and periotest study. Clin Implant Dent Relat Res. 2001;3(1):39-49.

28. Peñarrocha-Oltra D, Candel-Martí E, Ata-Ali J, Peñarrocha-Diago M Rehabilitation of the atrophic maxilla with tilted implants: review of the literature. J Oral Implantol. 2013;39(5):625-32.

29. Balleri P, Ferrari M, Veltri M. One-year outcome of implants strategically placed in the retrocanine bone triangle. Clin Implant Dent Relat Res. 2010;12(4):324-30.

30. Saleh Saber F, Ghasemi S, Koodaryan R, Babaloo A, Abolfazli N. The Comparison of Stress Distribution with Different Implant Numbers and Inclination Angles In All-on-four and Conventional Methods in Maxilla: A Finite Element Analysis. J Dent Res Dent Clin Dent Prospects. 2015;9(4):246253.

31. Li X, Cao Z, Qiu X, Tang Z, Gong L, Wang D. Does matching relation exist between the length and the tilting angle of terminal implants in the all-on-four protocol? Stress distributions by 3D finite element analysis. J Adv Prosthodont. 2015;7(3):240-248.

32. Barnea E, Tal H, Nissan J, Tarrasch R, Peleg M, Kolerman R. The Use of Tilted Implant for Posterior Atrophic Maxilla. Clin Implant Dent Relat Res 2016; 18(4)788-800. doi: 10.1111/cid.12342.

33. Nunes LS, Bornstein MM, Sendi P, Buser D. Anatomical characteristics and dimensions of edentulous sites in the posterior maxillae of patients referred for implant therapy. Int J Periodontics Restorative Dent. 2013;33(3):337-45.

34. Tolstunov L, Thai D, Arellano L. Implant-guided volumetric analysis of edentulous maxillary bone with cone-beam computerized tomography scan. Maxillary sinus pneumatization classification. $J$ Oral Implantol. 2012;38(4):377-90.

35. Candel-Marti E, Peñarrocha-Oltra D, Bagán L, Peñarrocha-Diago $M$, Peñarrocha-Diago M. Palatal positioned implants in severely atrophic maxillae versus conventional implants to support fixed fullarch prostheses: Controlled retrospective study with 5 years of follow-up. Med Oral Patol Oral Cir Bucal. 2015 1;20(3):357-64.

36. Gonda T, Kamei K, Maeda Y. Determining Favorable Maxillary Implant Locations Using ThreeDimensional Simulation Software and Computed Tomography Data. Int J Prosthodont. 2017;30(1):58-61.

37. Marquezan M, Osorio A, Sant'Anna E, Souza MM, Maia L. Does bone mineral density influence the primary stability of dental implant? A systematic review. Clin Oral Implants Res. 2012 Jul;23(7):76774.

38. De Bruyn H, Raes S, Ostman PO, Cosyn J. Immediate loading in partially and completely edentulous jaws: a review of the literature with clinical guidelines. Periodontol 2000. 2014 Oct;66(1):153-87. doi: 10.1111/prd.12040.

39. Katsumata A, Hirukawa A, Okumura S, Naitoh M, Fujishita M, Ariji E, et al. Relationship between density variability and imaging volume size in cone beam computerized tomographic scanning of the maxillofacial region: an in vitro study. Oral Surg Oral Med Oral Pathol Oral Radiol Endod 2009;107:420-425

Page $11 / 18$ 
40. Reeves TE, Mah P, McDavid WD. Deriving Hounsfield units using grey levels in cone beam CT: a clinical application. Dentomaxillofac Radiol. 2012 Sep;41(6):500-8.

41. Pauwels R, Jacobs R, Singer SR, Mupparapu M. CBCT-based bone quality assessment: are Hounsfield units applicable? Dentomaxillofac Radiol. 2015;44(1):20140238.

\section{Tables}




\begin{tabular}{|c|c|c|c|c|c|c|c|}
\hline RIGHT MAXILLA $30^{\circ}$ & $\mathrm{n}$ & mean & sd & median & $\min$ & $\max$ & range \\
\hline Alveolar.crest.height & 56 & 4.57 & 0.42 & 4.6 & 2.5 & 5 & 2.5 \\
\hline Implant.lenght & 56 & 13.22 & 2.97 & 13.38 & 7.07 & 19.26 & 12.19 \\
\hline Implant.diameter & 56 & 3.44 & 0.33 & 3.35 & 2.76 & 4.26 & 1.5 \\
\hline Palatal.angle & 56 & 5.93 & 8.04 & 6.23 & -24.27 & 31.52 & 55.79 \\
\hline Bone.quality & 56 & 566.57 & 124.74 & 567.5 & 274 & 822 & 548 \\
\hline RIGHT MAXILLA $45^{\circ}$ & $\mathrm{n}$ & mean & sd & median & $\min$ & $\max$ & range \\
\hline Alveolar.crest.height & 56 & 4.57 & 0.42 & 4.6 & 2.5 & 5 & 2.5 \\
\hline Implant.lenght & 56 & 14.31 & 2.91 & 14.27 & 9.21 & 22.63 & 13.42 \\
\hline Implant.diameter & 56 & 3.41 & 0.32 & 3.38 & 2.62 & 4.02 & 1.4 \\
\hline Palatal.angle & 56 & 5.2 & 7.6 & 5.72 & -21.19 & 26.72 & 47.91 \\
\hline Bone.quality & 56 & 565.91 & 125.51 & 567.5 & 274 & 822 & 548 \\
\hline LEFT MAXILLA $30^{\circ}$ & $\mathrm{n}$ & mean & sd & median & $\min$ & $\max$ & range \\
\hline Alveolar.crest.height & 54 & 4.63 & 0.36 & 4.8 & 3.9 & 5 & 1.1 \\
\hline Implant.lenght & 54 & 12.85 & 3.28 & 12.96 & 6.32 & 19.49 & 13.17 \\
\hline Implant.diameter & 54 & 3.43 & 0.32 & 3.36 & 2.8 & 4.39 & 1.59 \\
\hline Palatal.angle & 54 & 6.67 & 6.52 & 7.36 & -10.44 & 23.33 & 33.77 \\
\hline Bone.quality & 54 & 573.43 & 127.59 & 559.5 & 282 & 934 & 652 \\
\hline LEFT MAXILLA $45^{\circ}$ & $\mathrm{n}$ & mean & sd & median & $\min$ & $\max$ & range \\
\hline Alveolar.crest.height & 54 & 4.63 & 0.36 & 4.8 & 3.9 & 5 & 1.1 \\
\hline Implant.lenght & 54 & 13.65 & 3.01 & 13.86 & 8.34 & 20.86 & 12.52 \\
\hline Implant.diameter & 54 & 3.37 & 0.31 & 3.34 & 2.63 & 4.07 & 1.43 \\
\hline Palatal.angle & 54 & 5.29 & 6.66 & 6.01 & -10.93 & 23.33 & 34.25 \\
\hline Bone.quality & 54 & 571.8 & 130.92 & 559.5 & 282 & 952 & 670 \\
\hline
\end{tabular}




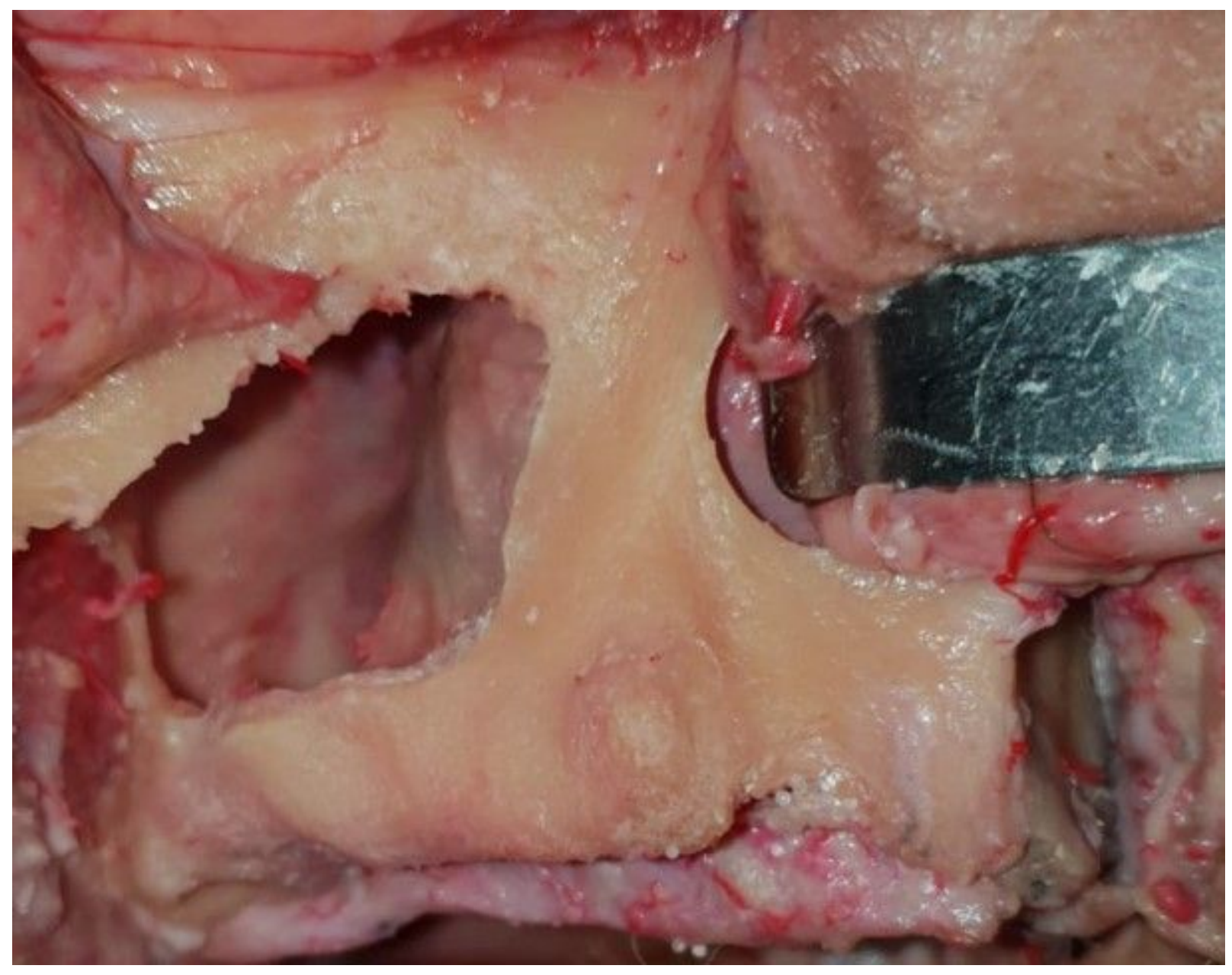

\section{Figure 1}

The mid-maxilla region is shown in this fresh frozen ex vivo fixed specimen. The vestibular wall of the right sinus has been removed in order to expose the extension of the paranasal cavity. The residual alveolar bone around the canine region is the area of interest for tilted implant positioning.

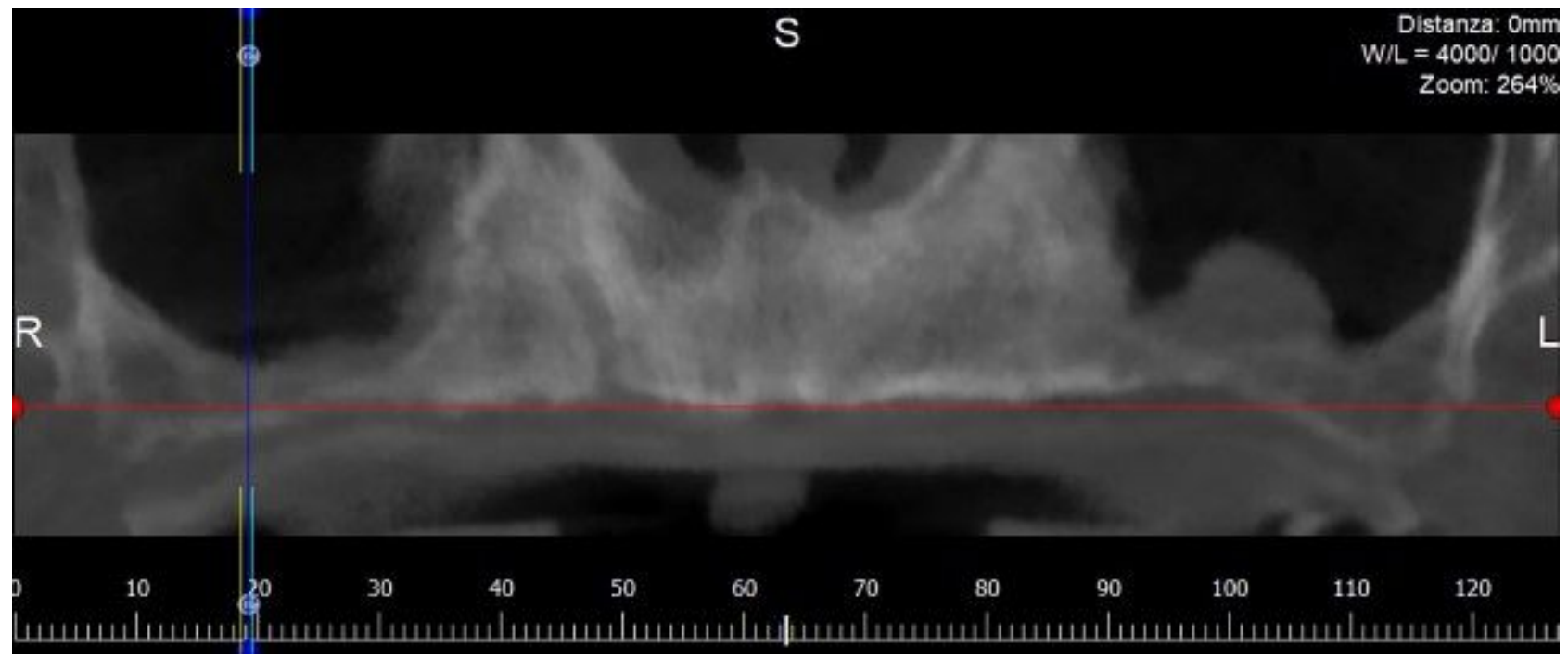

Figure 2 


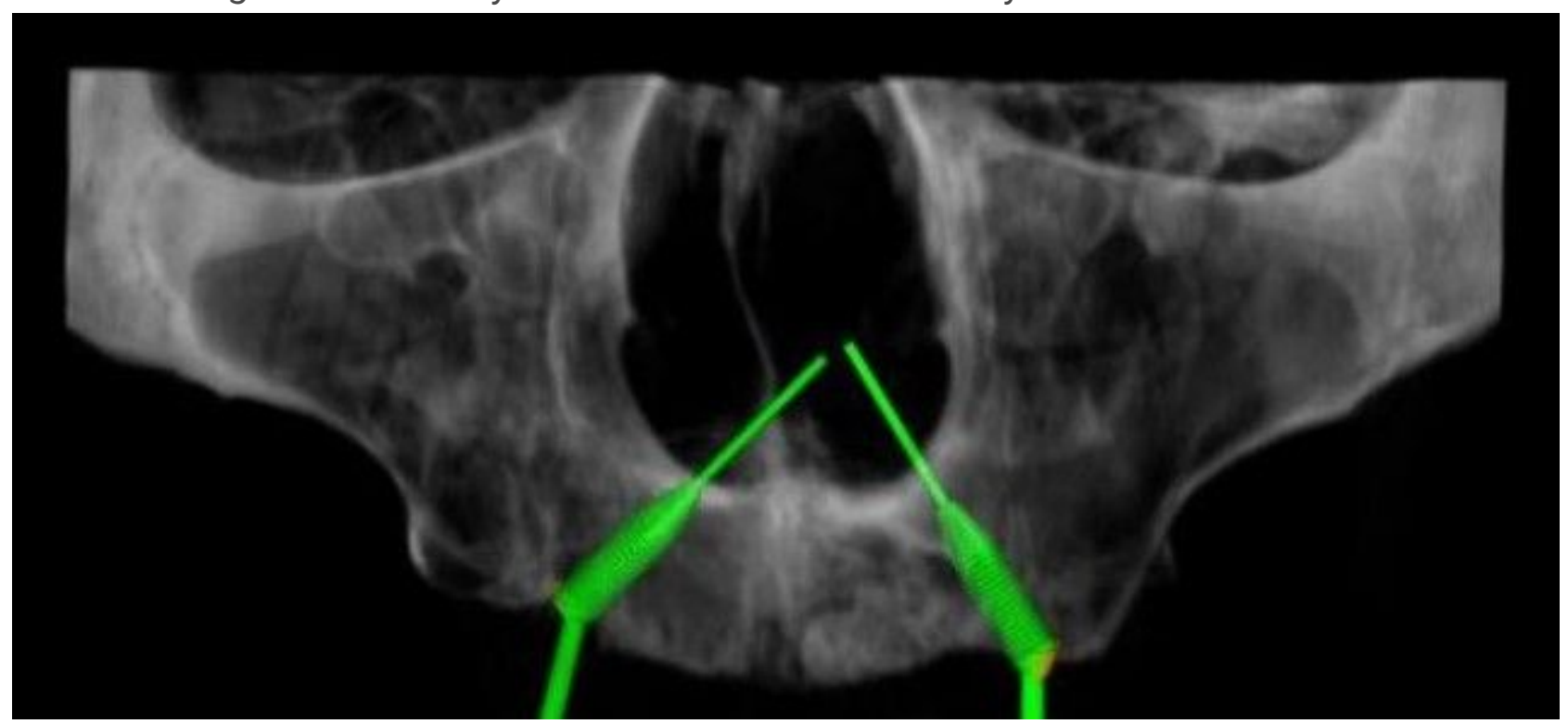

Figure 3

In this 3D reconstruction the iuxtameatal implant was placed in the right maxilla with $45^{\circ}$ of angulation, in the left side with $30^{\circ}$ of angulation.

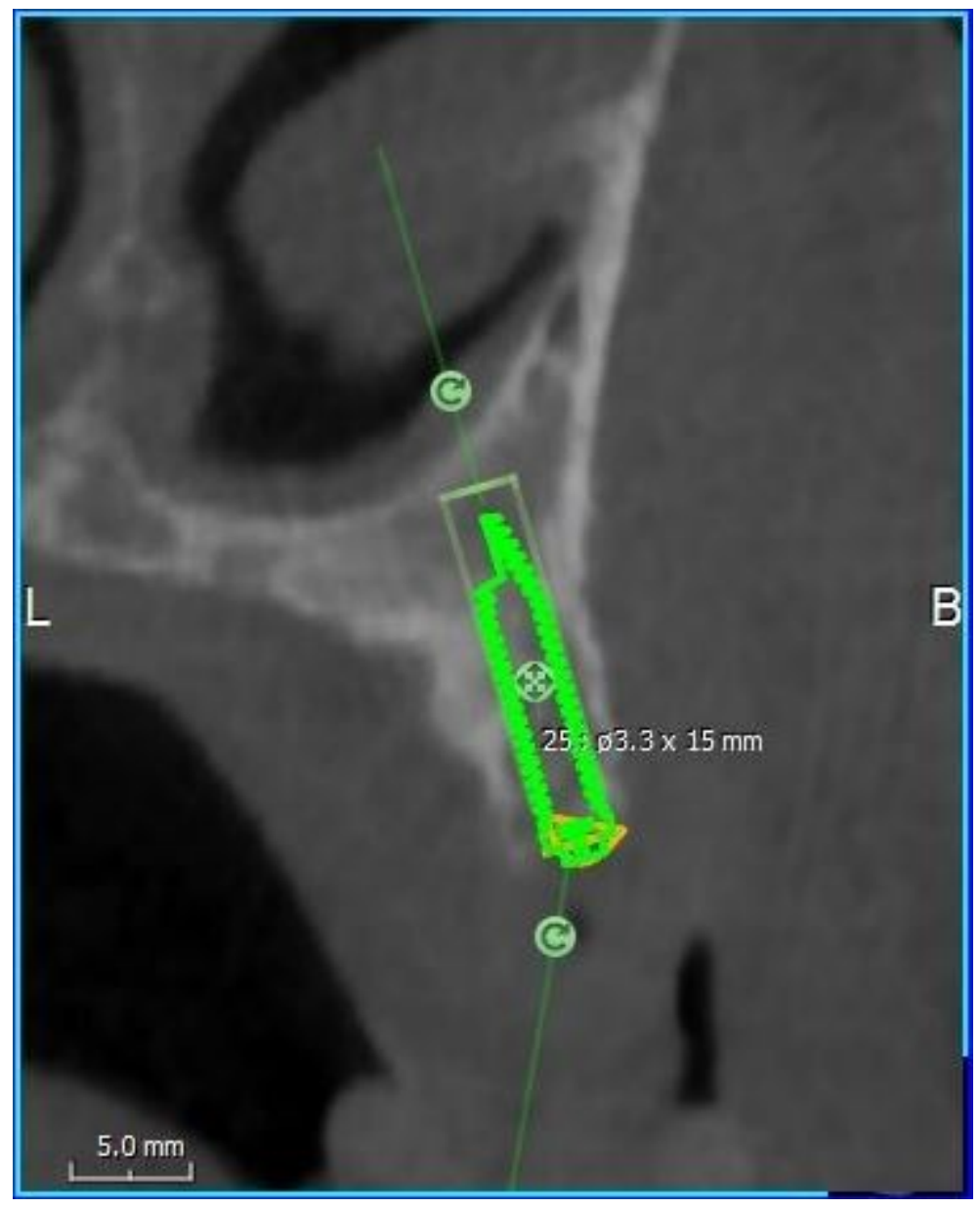

Figure 4 
Cross sectional view during the iuxtameatal implant positioning in the left side with $2 \mathrm{~mm}$ of bone all around the fixture.

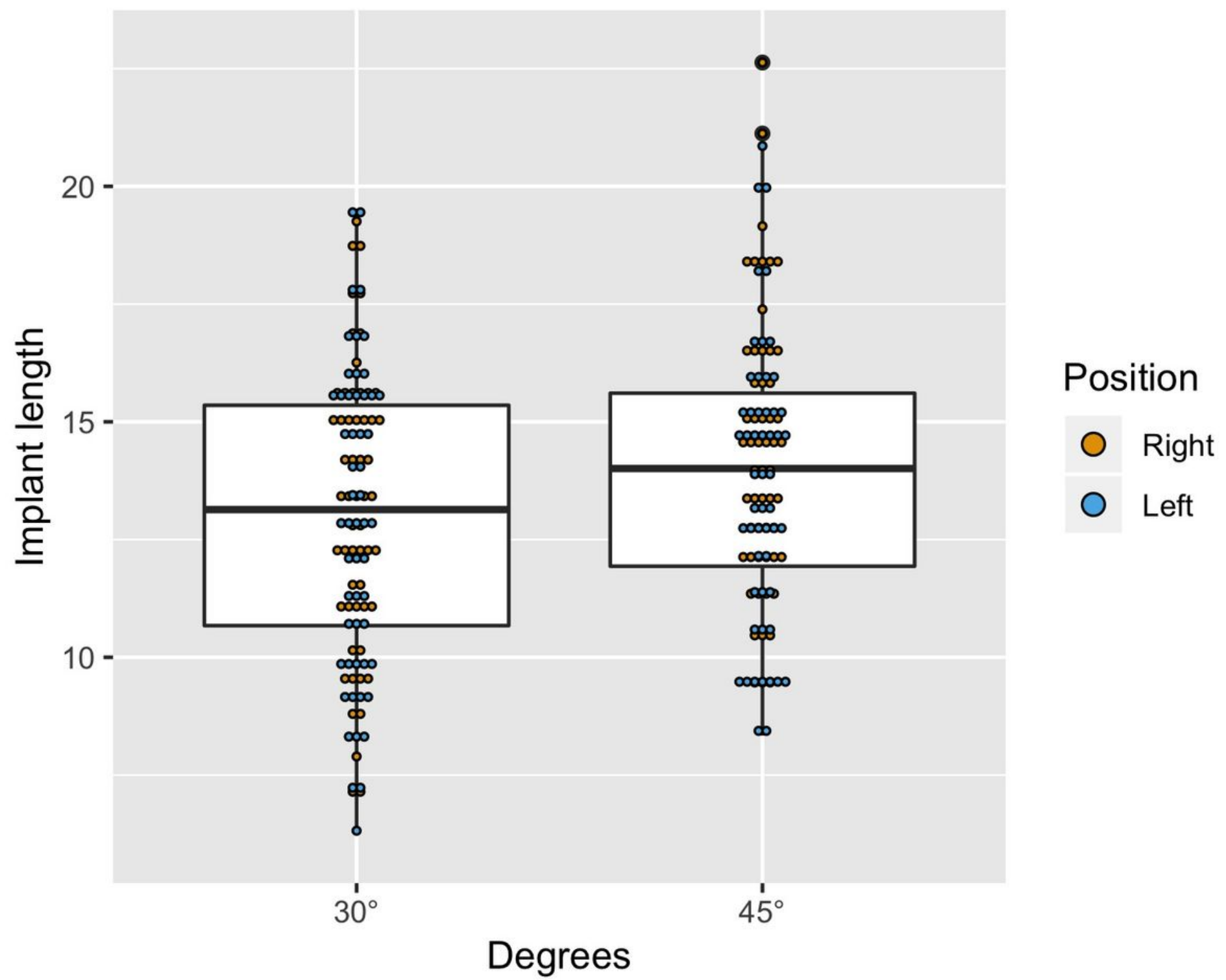

Figure 5

Boxplot showing the distribution of implant length by position and degrees. 


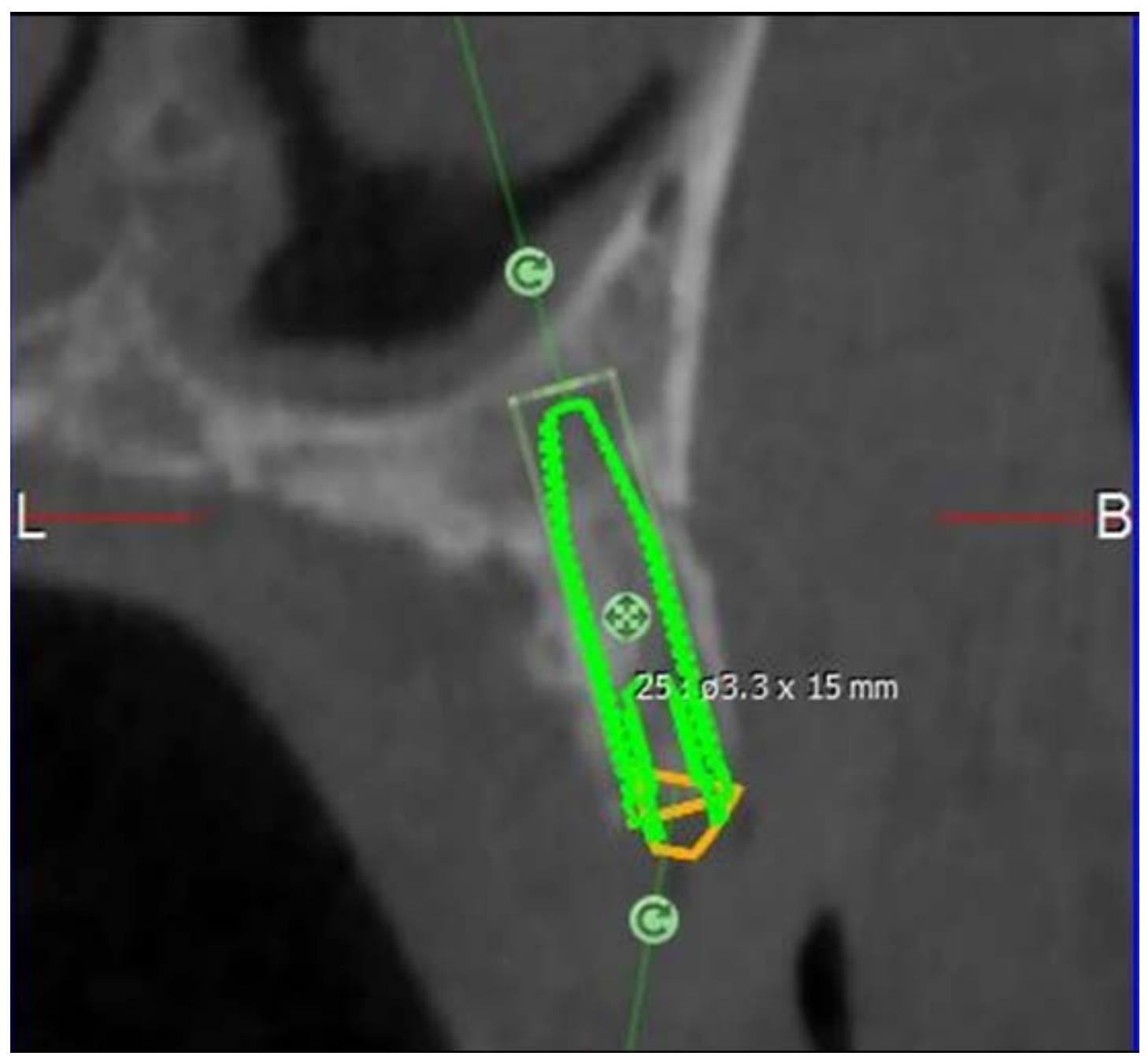

Figure 6

Cross sectional view during the iuxtameatal implant positioning in the left side with a positive buccalpalatal angle.

B

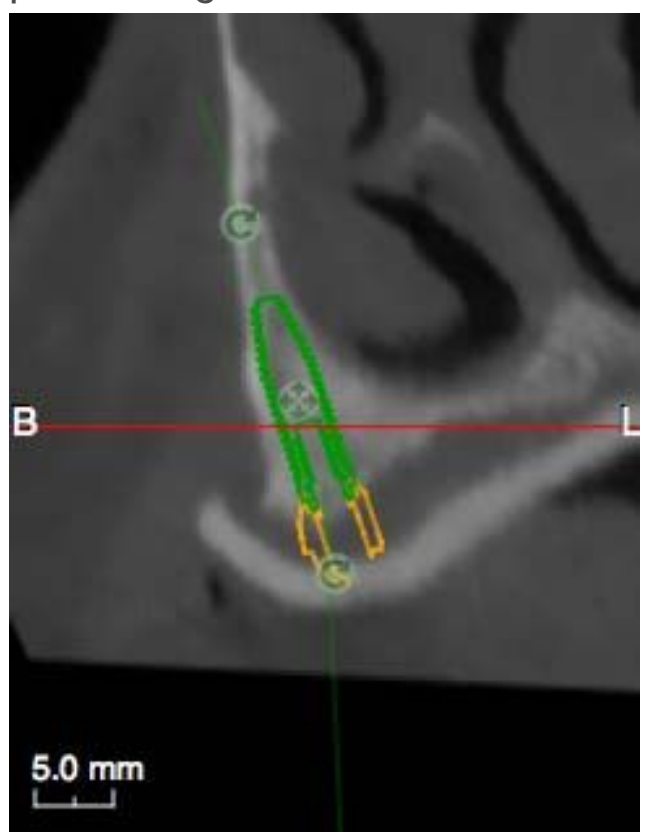


Figure 7

Cross sectional view during the iuxtameatal implant positioning in the right side with a negative buccalpalatal angle.

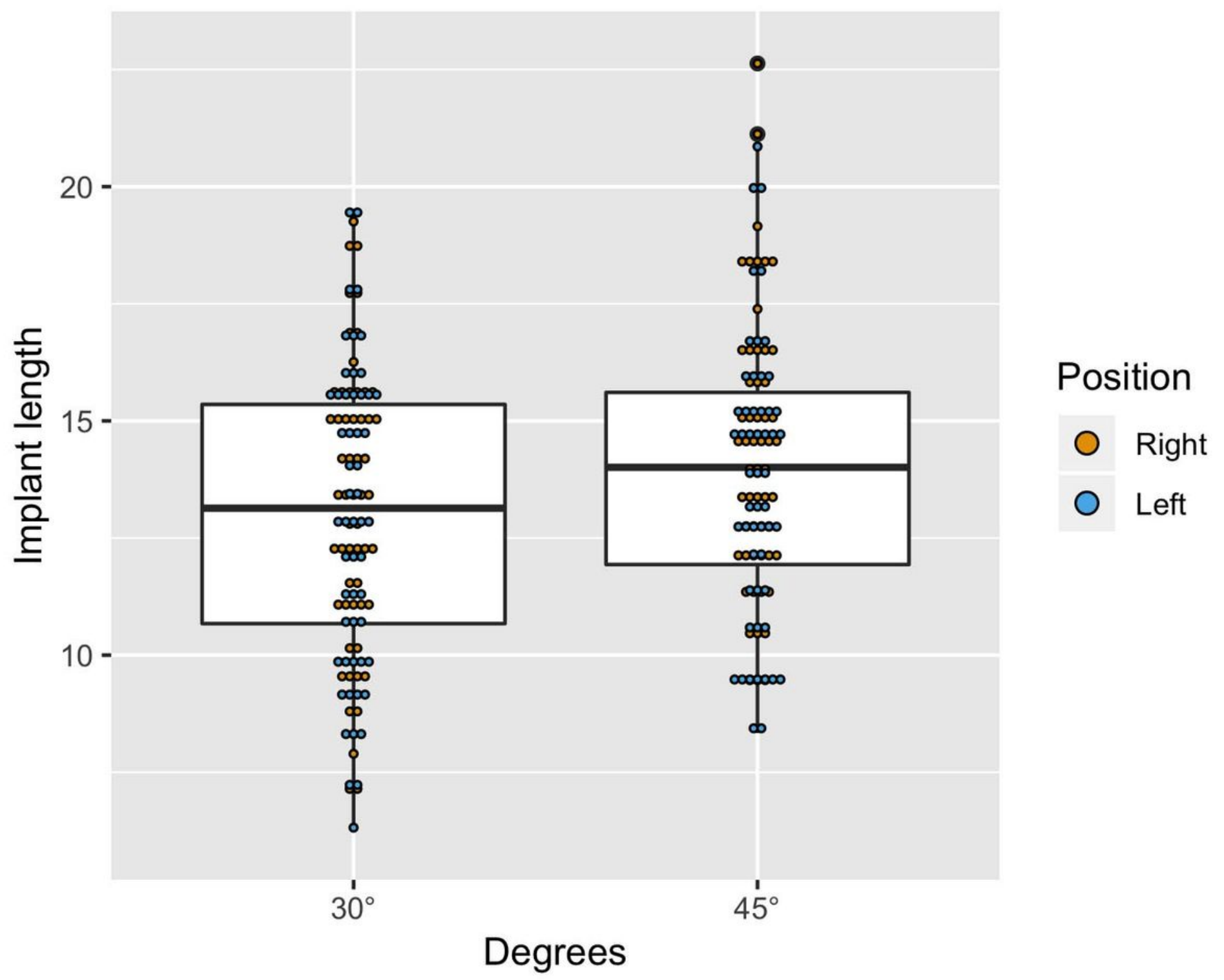

Figure 8

Boxplot showing the distribution of implant length by position and degrees.

\section{Supplementary Files}

This is a list of supplementary files associated with this preprint. Click to download.

- Outcomes.xIsx 